\title{
Soil moisture modelling of a SMOS pixel: interest of using the PERSIANN database over the Valencia Anchor Station
}

\author{
S. Juglea ${ }^{1}$, Y. Kerr ${ }^{1}$, A. Mialon ${ }^{1}$, E. Lopez-Baeza ${ }^{2}$, D. Braithwaite ${ }^{3}$, and K. Hsu ${ }^{3}$ \\ ${ }^{1}$ Centre d'Études Spatiales de la BIOsphère, UMR5126 (CNRS, CNES, IRD, UPS), Toulouse, France \\ ${ }^{2}$ Universitat de Valencia, Departament de Termodinamica i Fisica de la Terra, Valencia, Spain \\ ${ }^{3}$ Center for Hydrometeorology and Remote Sensing (CHRS), Civil and Environmental Engineering, UC IRvine, \\ Irvine CA 92697-2175, USA
}

Received: 8 February 2010 - Published in Hydrol. Earth Syst. Sci. Discuss.: 11 February 2010

Revised: 21 July 2010 - Accepted: 2 August 2010 - Published: 10 August 2010

\begin{abstract}
In the framework of Soil Moisture and Ocean Salinity (SMOS) Calibration/Validation (Cal/Val) activities, this study addresses the use of the PERSIANN-CCS ${ }^{1}$ database in hydrological applications to accurately simulate a whole SMOS pixel by representing the spatial and temporal heterogeneity of the soil moisture fields over a wide area $\left(50 \times 50 \mathrm{~km}^{2}\right)$. The study focuses on the Valencia Anchor Station (VAS) experimental site, in Spain, which is one of the main SMOS Cal/Val sites in Europe.

A faithful representation of the soil moisture distribution at SMOS pixel scale $\left(50 \times 50 \mathrm{~km}^{2}\right)$ requires an accurate estimation of the amount and temporal/spatial distribution of precipitation. To quantify the gain of using the comprehensive PERSIANN database instead of sparsely distributed rain gauge measurements, comparisons between in situ observations and satellite rainfall data are done both at point and areal scale. An overestimation of the satellite rainfall amounts is observed in most of the cases (about 66\%) but the precipitation occurrences are in general retrieved (about $67 \%$ ).

To simulate the high variability in space and time of surface soil moisture, a Soil Vegetation Atmosphere Transfer (SVAT) model - ISBA (Interactions between Soil Biosphere Atmosphere) is used. The interest of using satellite rain-
\end{abstract}

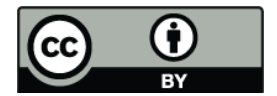

Correspondence to: S. Juglea

(silvia.juglea@cesbio.cnes.fr)

\footnotetext{
${ }^{1}$ Precipitation Estimation from Remotely Sensed Information using Artificial Neural Networks-Cloud Classification System http://chrs.web.uci.edu/persiann
}

fall estimates as well as the influence that the precipitation events can induce on the modelling of the water content in the soil is depicted by a comparison between different soil moisture data. Point-like and spatialized simulated data using rain gauge observations or PERSIANN - CCS database as well as ground measurements are used. It is shown that a good adequacy is reached in most part of the year, the precipitation differences having less impact upon the simulated soil moisture. The behaviour of simulated surface soil moisture at SMOS scale is verified by the use of remote sensing data from the Advanced Microwave Scanning Radiometer on Earth observing System (AMSR-E). We show that the PERSIANN database provides useful information at temporal and spatial scales in the context of soil moisture retrieval.

\section{Introduction}

Solid knowledge of spatial and temporal soil moisture dynamics is essential in hydrological and meteorological modelling to improve our understanding of land-surfaceatmosphere interactions. Numerous studies have shown the potential of using satellite data for the assessment of surface soil moisture at global scale. Particularly, passive Lband microwave radiometry has proven promising to approach this difficult task due the soil penetration depth, and the fact that it is passive and thus rather insensitive to structural features - on top of its ability to go through vegetation and atmosphere with much less alterations than longer wavelengths and active systems (Wang et al., 1990a; Schmugge et al., 1992; Jackson et al., 1995, 1999). The Soil Moisture

Published by Copernicus Publications on behalf of the European Geosciences Union. 
and Ocean Salinity (SMOS) mission carrying the first spaceborne passive L-band radiometer on board, has recently been launched by ESA. One of its main objectives is the mapping of global surface soil moisture fields with an accuracy better than $0.04 \mathrm{~m}^{3} \mathrm{~m}^{-3}$ and a temporal resolution of 2-3 days (Kerr et al., 2001).

The validation and calibration of the SMOS measurements is a crucial phase of the mission. In this context, representative values of soil moisture and brightness temperature for an entire SMOS pixel comparable to the satellite product at any overpass time are needed. To achieve a representative value of SMOS's footprint, it is essential to characterize and monitor an area slightly larger than the actual pixel ( $3 \mathrm{~dB}$ footprint) in terms of soil moisture/brightness temperature. Considering the antenna pattern of SMOS, an area of $55 \mathrm{~km}$ over land $(43 \mathrm{~km}$ on average over the field of view) is seen by the instrument. However, observing the spatial distribution of soil moisture at the catchment (areal) scale by means of point is situ measurements is a difficult task. Dense sampling is required to achieve a good accuracy which is very costly and labour-intensive. To overcome these limitations, one issue currently under study is to use a Soil-Vegetation-Atmosphere-Transfer (SVAT) model to obtain distributed soil moisture fields. Juglea et al. (2010) proved the ability of the SVAT scheme (SURFEX (Externalized Surface) - module ISBA (Interactions between SoilBiosphere-Atmosphere) (Noilhan and Planton, 1989; Noilhan and Mahfouf, 1996) to simulate the high temporal and spatial heterogeneity of soil moisture over the Valencia Anchor Station (VAS) experimental site in Spain by using in situ point measurements for model calibration and validation. VAS was selected as a key site providing in situ geophysical measurements over an area as wide as a SMOS pixel (LopezBaeza et al., 2005a; Delwart et al., 2007).

At SMOS pixel scale $\left(50 \times 50 \mathrm{~km}^{2}\right)$ soil moisture variability is mostly driven by atmospheric forcing effects, thus mainly being influenced by climatic conditions at large scale and precipitation. Since precipitation is considered as an important factor in controlling spatial and temporal patterns of soil moisture, especially in arid and semiarid regions (Grayson et al., 2006), a good estimation of water content in the soil requires an understanding of the spatial and temporal variability of the rainfall. In fact, rainfall data availability has been highlighted as a major constraint on the effective application of water resource models, and it has been argued that quality of rainfall model inputs is often more important than the choice of the model itself (Wilk et al., 2006). Spatial rainfall estimates derived from rain-gauges are widely used as input to hydrological models and as "ground truth" for satellite rainfall measurements (Seed and Austin, 1990). However, again these in situ measurements are often sparsely and irregularly distributed in space which questions their representativeness of an area of SMOS pixel size. The incorporation of satellite-based rainfall estimates in hydrological modelling is expected to offer an alternative to ground based rainfall observations. The use of satellite-based information to improve spatial rainfall estimates has been widely reported (Hsu et al., 1999; Sorooshian et al., 2000; Grimes and Diop, 2003). However, so far few studies have investigated the application of these data sets in hydrological models. Studies were conducted to evaluate the performance of hydrological models using operational satellite rainfall estimates in Southern Africa (Thorne et al., 2001; Hughes et al., 2006; Hughes, 2006; Wilk et al., 2006). Hughes (2006) concluded that the satellite rainfall data do not reflect the strong influences on precipitation of topography in some of the basins. However, the preliminary results obtained in four studied areas representing very different climate regimes within Southern Africa are encouraging enough to suggest that further investigations are justified. Collischonn et al. (2008) evaluated the rainfall estimates of the Tropical Rainfall Measuring Mission (TRMM) satellite over the Tapajos river basin in Amazon. They concluded that it is very unlikely that remote sensing of precipitation will completely replace ground based measurements, but that it is possible that the best information for hydrological applications will be the combination of remote sensing and ground data. Gottschalck et al. (2005) and Ming et al. (2010) carried out studies over the continental United State region. Gottschalck et al. (2005) studied the impact of different precipitation products on soil state, while Ming et al. (2010) forced a Land Surface Model with both satellite estimates and in situ rainfall measurements to test how well they can predict hydrologic states and fluxes useful for water resource applications. They confirmed that global precipitation measurement from space offers great value for hydrology and water resource applications, especially for areas with lack of ground measurements. However, depending on the specific purpose of the application, such as drought monitoring or flooding forecasting, continued research is required before satellite rainfall products are skillful enough for operational use.

A database with high potential to improve spatial rainfall estimates and thus modeled soil moisture data at SMOS pixel scale especially in areas where rain gauge stations are absent or sparse is the PERSIANN-CCS (Precipitation Estimation from Remotely Sensed Information using Artificial Neural Networks-Cloud Classification System - http:// chrs.web.uci.edu/persiann) satellite rainfall data (Hong et al., 2004). With $0.04 \times 0.04^{\circ}$ spatial and $1 \mathrm{~h}$ temporal resolution it belongs to the satellite rainfall databases with currently best resolutions, and corresponds well with the high resolution grid used in the SMOS soil moisture retrieval scheme (see the ATBD document - www.cesbio.ups-tlse.fr/fr/smos/ smos_atbd.html). Hughes (2006) found high correlation between PERSIANN estimates with single point rain gauges in a number of basins in Southern Africa, while Gottschalck et al. (2005) reported that in the central United States PERSIANN suffers from a few deficiencies-most notably an overestimation of summertime precipitation (200-400 mm). 
The objective of this paper is to investigate the benefit of applying the PERSIANN database to reproduce the high temporal and spatial heterogeneity of soil moisture fields at SMOS pixel scale over the VAS test site compared to using sparsely and irregularly distributed in situ rain gauge measurements. For this purpose, the SVAT scheme SURFEX - module ISBA originally driven by sparse in situ meteorological measurements over VAS (Juglea et al., 2010) is also forced with satellite rainfall data from the PERSIANN database. First, the skill of the PERSIANN products to replicate the variability of gauge rainfall amounts and occurrence at point and areal scale is tested. Then, the PERSIANN rainfall data is input to the ISBA model to simulate the spatial and temporal heterogeneity of soil moisture fields at point and spatialized scale. These simulations are compared with in situ soil moisture measurements as well as soil moisture estimates obtained from simulations using in situ rain gauge data again at both scales. The spatialized soil moisture product obtained using PERSIANN estimates is compared with remote sensing soil moisture product available at this time. In this framework, the behaviour at the SMOS footprint scale of the spatialized soil moisture product obtained using PERSIANN rainfall was tested by using remote sensing products derived from AMSR-E (Advanced Microwave Scanning Radiometer of the Earth Observing System).

\section{Studied area and data}

\subsection{Valencia Anchor Station}

The Valencia Anchor Station (VAS) is located in Eastern Spain, about $80 \mathrm{~km}$ inland to the West of Valencia. The site was selected by ESA with the main objective to characterize a large-scale reference area. It is dedicated specifically to the validation and calibration of low spatial resolution Earth Observation data and products. The site, defined within the natural region of the Utiel-Requena Plateau, represents a reasonably homogeneous area of about $50 \times 50 \mathrm{~km}^{2}$ (Lopez-Baeza et al., 2008), mainly dedicated to vineyard crops (about $56 \%$ cover), and other Mediterranean land uses (shrubs, oaks, pine, olive and almond trees, etc). The soil types are Haplic and Petrocalcic Calcisols, and Calcaric Cambisols, and are deep with accumulation of carbonates and with low organic matter content (Lopez-Baeza et al., 2008). Considering the wavelength of observation $(\lambda=21 \mathrm{~cm})$, the area remains as a ploughed bare soil for about half a year.

VAS is a semiarid environment with low annual precipitation (around $400 \mathrm{~mm}$ ) and is characterized by an extensive set of measurements at different levels (both in the atmosphere and in the soil) in order to derive surface energy fluxes. Over the VAS area $\left(50 \times 50 \mathrm{~km}^{2}\right) 22$ meteorological stations, 4 fully equipped and 18 rain gauges, are randomly and not uniformly distributed (Fig. 1). The 4 fully equipped stations provide meteorological data: air temperature and hu-

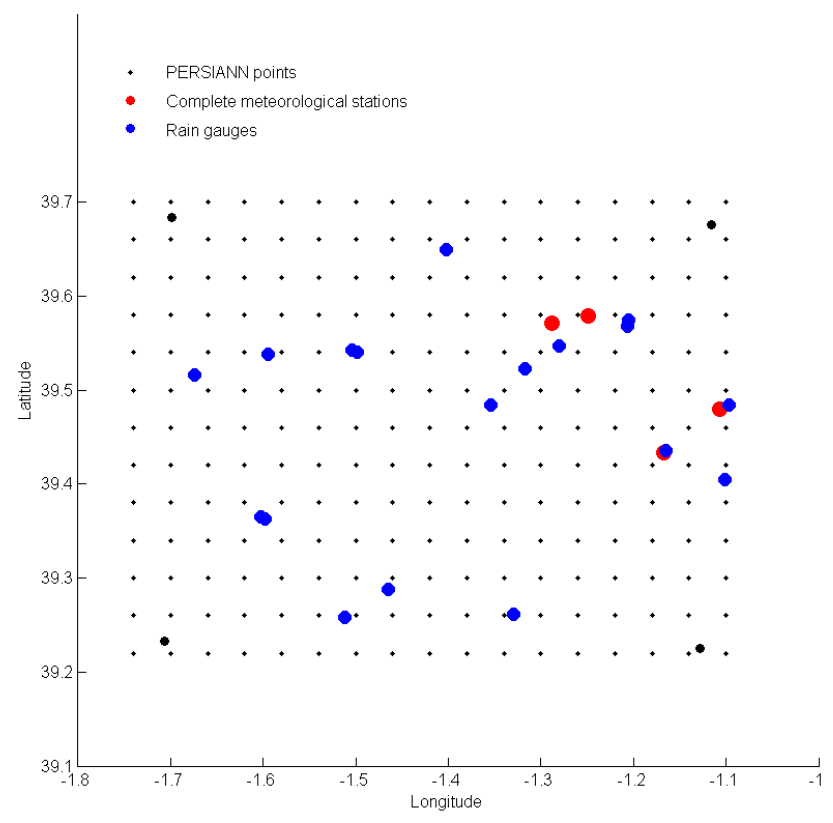

Fig. 1. Distribution of the in situ meteorological stations (red dots) and rain gauges (blue dots) over the $50 \times 50 \mathrm{~km}^{2}$ VAS area (the four large black dots representing its limits). The PERSIANN points are represented in small black dots.

midity at screen level, atmospheric pressure, precipitation, wind speed and direction and solar and atmospheric radiation. The atmospheric forcing is used as an input to the SVAT model to obtain the surface soil moisture. According to the dataset, in the 4 fully equipped meteorological stations located into the VAS $50 \times 50 \mathrm{~km}^{2}$ area, the measured data are registered on a 30/60 min basis: air temperature and humidity at screen level, atmospheric pressure, precipitation, wind speed and direction, and solar and atmospheric radiation. In addition, among the rain gauges, some of them are recording the weather information daily. In order to run the SVAT models with a suitable temporal resolution, standard diurnal cycles are reconstructed from the daily data.

Over the $50 \times 50 \mathrm{~km}^{2}$ area in situ soil moisture measurements are available. In this study, soil moisture data recorded during the Mediterranean Ecosystem L-Band characterization Experiment 2 (Melbex $2-39.526^{\circ} \mathrm{N}, 1.288^{\circ} \mathrm{W}$ ) is used. The campaign was carried out from April 2007 to December 2007 to observe the surface emission of vineyards (Cano et al., 2008). The soil is characterized as sandy clay loam, with a texture composed of $45 \%$ sand and $26 \%$ clay. The soil moisture measurements were carried out at $5 \mathrm{~cm}$ depth within an area of about $2 \mathrm{~m}^{2}$ every $10 \mathrm{~min}$ using three capacitive probes. In the area, the soil was ploughed at least 3 times during the growing period of vineyards.

Surface static fields (vegetation fraction, roughness, leaf area index (LAI), soil texture, and others) are accessible. 
A detailed description of the vegetation characteristics is available at $1 \mathrm{~km}$ resolution based on ECOCLIMAP, a surface parameter database derived from land cover and climatic maps (Masson et al., 2003). The LAI data comes from the MODIS instrument (Moderate Resolution Imaging Spectroradiometer; http://modis.gsfc.nasa.gov/) at $1 \mathrm{~km}$ spatial resolution provided on a daily and 8-day basis. An accurate map representing the spatial distribution of clay and sand (MillanScheiding et al., 2008) at $10 \mathrm{~m}$ resolution covering all the $50 \times 50 \mathrm{~km}^{2}$ area is available.

\subsection{PERSIANN database}

The PERSIANN system for rainfall estimation is under development at The Center for Hydrometeorology and Remote Sensing at The University of California, Irvine. The fundamental algorithm is based on a neural network and can therefore be easily adapted to incorporate relevant information as it becomes available. The original system (Hsu et al., 1997) was based on geostationary infrared imagery and later extended (Hsu et al., 1999) to include the use of both infrared and daytime visible imagery. Further development of PERSIANN has included cloud image segmentation and classification for rainfall estimation at $0.04 \times 0.04^{\circ}$ resolution (Hong et al., 2004). Instead of extracting local texture information in PERSIANN (Hsu et al., 1997, 1999; Sorooshian et al., 2000), PERSIANN-CCS extracts information from the whole cloud patch and provides multiple infrared brightness temperature versus rainfall rate $(T b-R)$ relationships for different cloud classification types.

The product used in this study is PERSIANN - CCS, hereafter referenced as PERSIANN. It exhibits $0.04 \times 0.04^{\circ}$ spatial and $1 \mathrm{~h}$ temporal resolution with complete coverage between $60^{\circ} \mathrm{S}$ to $60^{\circ} \mathrm{N}$. The VAS area includes 221 PERSIANN grid points (see Fig. 1).

\subsection{AMSR-E data}

The Advanced Microwave Scanning Radiometer (AMSR) of the Earth Observing System (EOS) is a passive microwave scanning radiometer, operating in horizontal and vertical polarizations at six wavelengths $(6.925,10.65,18.7,23.8,36.5$, and $89 \mathrm{GHz}$ ) with an incidence angle of $55^{\circ}$. Launched on the Aqua satellite in May 2002, it operates in polar sunsynchronous orbit with equator crossing at 01:30 p.m. and 01:30 a.m. local solar time. Global coverage is achieved every two days or less depending on the latitude. The mean spatial resolution at $6.9 \mathrm{GHz}$ is about $56 \mathrm{~km}$. The data used in this study are AMSR-E Level 3 soil moisture and brightness temperature at $6.9 \mathrm{GHz}$ (Njoku, 2004), and are provided by the National Snow and Ice Data Center (NSIDC). The inversion algorithm for the AMSR-E soil moisture uses the 10.7 GHz and $18.7 \mathrm{GHz}$ brightness temperature data (Njoku et al., 2003). The increased signal attenuation by vegetation and the superficial sensing depth for higher frequencies is a limit in the soil moisture retrieval from AMSR-E data. Thus, the polarization ratio is additionally used as it provides a better agreement (than the soil moisture product from AMSR-E) with simulated soil moisture even in the vegetation growing period (Juglea et al., 2010). By means of the $6.9 \mathrm{GHz}$ horizontally (h) and verticaly (v) polarized brightness temperatures we computed the polarization ratio (PR) as following:

$\mathrm{PR}=\frac{T b_{\mathrm{v}}-T b_{\mathrm{h}}}{T b_{\mathrm{v}}+T b_{\mathrm{h}}}$

The advantage of using the PR is that it normalizes out the surface temperature and leaves a quantity that depends primarily on soil moisture, vegetation and atmosphere (Kerr and Njoku, 1990; Njoku et al., 2003; Owe et al., 2001). The AMSR-E brightness temperature and soil moisture products are re-sampled to a global cylindrical $25 \mathrm{~km}$ EqualArea Scalable Earth Grid (EASE-Grid) cell spacing (Njoku, 2004). Two AMSR-E pixels are covering the VAS area. The average of these two pixels is considered to be representative for the $50 \times 50 \mathrm{~km}^{2}$ area corresponding to one SMOS pixel.

\section{Methodology - ISBA modelling}

The model used to generate the temporal behaviour of the soil moisture from atmospheric forcing and initial conditions is called SURFEX (stands for surface externalisée Le Moigne et al., 2009) and was developed at the National Center for Meteorological Research (CNRM) at MétéoFrance. It gathers all the developments and improvements made in surface schemes, and contains four different modules: ISBA (Interactions between Soil-BiosphereAtmosphere), Sea and ocean, TEB (Town Energy Balance) and Lake. For this work only the ISBA module (Noilhan and Planton, 1989; Noilhan and Mahfouf, 1996) is used. It simulates the interaction between the low-level atmosphere, the vegetation and the soil, by using a physically based method that solves the water and energy budgets of the soilvegetation system. In this study, the modelling of the heat and water transfers into the soil is based on the diffusive scheme - ISBA-DIF (Boone, 2000; Boone et al., 2000). Details on the choice of the parametrization can be found in Juglea et al. (2010). The atmospheric forcing required to run the ISBA model is composed of: air temperature and humidity at screen level, atmospheric pressure, precipitation, wind speed and direction and solar and atmospheric radiation. The soil layer discretization was chosen so as to enable comparisons of realistic configurations as a function of the penetration depth, between ground measurements and/or the remote sensing data, from $1 \mathrm{~cm}$ at the surface down to $1.50 \mathrm{~m}$ of depth $(1,2,3,4,5,7,9,10,30,50,80,100,150 \mathrm{~cm})$. The soil moisture modelling is done in two steps: one consisted in a point modelling, followed by a spatialized one. 
The data processed is either in situ data from VAS (meteorological observations and surface state characteristics) area either remote sensed data from PERSIANN (rainfall estimates). The two procedures are illustrated next.

\subsection{Point procedure}

In the point procedure the ISBA model is forced in different point locations. As the goal of this study is to evaluate the influence of precipitation on the soil moisture simulations, different rainfall data, namely in situ measurements from the two rain gauges "Caudete de las Fuentes" (CA FU $-1.32^{\circ} \mathrm{W}$, $39.52^{\circ} \mathrm{N}$ ), and "Caudete de las Fuentes 1" (CA FU1 $1.28^{\circ} \mathrm{W}, 39.55^{\circ} \mathrm{N}$ ) and the closest PERSIANN point PP148 $\left.1.30^{\circ} \mathrm{W}, 39.54^{\circ} \mathrm{N}\right)($ Fig. 3), were input to the model while a common set of surface characteristics and atmospheric forcing was used for each of the three model runs. Analysis of the simulated soil moisture as well as comparisons with ground measurements are presented in Sect. 4.2.1.

\subsection{Spatialized procedure}

In order to reproduce the high temporal and spatial heterogeneity of soil moisture over the VAS site, in the spatialized procedure the ISBA model is run over a regular grid covering the entire area. Thereby, two scenarios were investigated, (a) using precipitation data from the 22 in situ rain gauges and meteorological stations, and (b) using satellite precipitation data from the 221 PERSIANN points within the VAS area. For both scenario runs, the input data first had to be prepared by interpolation to a common grid, though with differing grid cell sizes for the two scenarios according to the respective spatial availability of the applied precipitation data. In case of scenario (a) the $50 \times 50 \mathrm{~km}^{2}$ area was divided into $10 \times 10 \mathrm{~km}^{2}$ cells. Figure 1 presents the spatial distribution of the available meteorological stations/rain gauges over the VAS. As an irregular distribution of the stations can be noticed (for example in the center of the area there is no data) an interpolation (Inverse Distance Weighted - IDW) of all the available meteorological stations is performed over the $10 \times 10 \mathrm{~km}^{2}$ grid as described in Juglea et al., 2010. In case of scenario (b) the $50 \times 50 \mathrm{~km}^{2}$ area was divided into $4 \times 4 \mathrm{~km}^{2}$ cells corresponding to the resolution of the PERSIANN grid $\left(0.04 \times 0.04^{\circ}\right)$. Temperature, atmospheric pressure, wind speed, wind direction and relative humidity data from the 4 complete meteorological stations were interpolated over this grid using IDW. The downwelling shortwave fluxes from the Land-SAF radiation product (http://landsaf.meteo.pt/) were extracted over the same grid while the longwave fluxes were calculated using the interpolated data and the formulation from Brutsaert (1975) which uses only inputs of measured surface air temperature and moisture amount. The roughness and the fraction of vegetation (ECOCLIMAP) and the LAI (MODIS), are at $1 \mathrm{~km}$ resolution. Due to their different spatial resolutions when compared to the $4 \times 4 \mathrm{~km}^{2}$ grid, these products were aggregated through a spatial mean. Texture maps (sand and clay) are available at $10 \mathrm{~m}$ resolution. In this case, the aggregation to the $4 \times 4 \mathrm{~km}^{2}$ was accomplished by considering the main class of texture into the grid cell. The ISBA-model was then driven by means of the respective precipitation data, atmospheric forcing and land surface data grids for the two scenarios (a) and (b) at an hourly time-step to obtain spatially distributed soil moisture datasets for the VAS site. For each scenario the respective soil moisture grid was averaged to one representative soil moisture value for the entire $50 \times 50 \mathrm{~km}^{2}$ area comparable to satellite products resolution. To check the behaviour of both spatialized soil moisture datasets (simulated by means of in situ observations or PERSIANN satellite estimates) a comparison with existing products derived from AMSR-E is performed over a 2-year period. The soil moisture simulations are extracted for the time steps close to the satellite overpass times. As AMSRE penetration depth is about $2 \mathrm{~cm}$, the simulated soil moisture integrated over the first $2 \mathrm{~cm}$ is considered. Comparisons between the simulated soil moisture datasets using different precipitation input at both point and spatialized scales as well as comparisons of spatialized soil moisture simulations and remote sensing products from AMSR-E are presented in following paragraphs.

\section{Results and discussion}

In order to test the ability of the PERSIANN satellite rainfalls to be used as an input of a hydrological model so as to accurately simulate a whole SMOS pixel, an evaluation of the product is undertaken. In this chapter results of the conducted analyses are presented and discussed. Firstly, rain rates comparisons between in situ rainfall observations and the PERSIANN points are shown at both point and areal scale. Secondly, the ISBA soil moisture simulations over the VAS site at point and spatialized scale using the two scenarios with (a) in situ meteorological observations and (b) the PERSIANN database as input are illustrated. Results of the two scenario runs are compared with ground measurements as well as with each other. Thirdly, comparisons of the spatialized soil moisture simulations from the two scenarios with AMSR-E products over a two-year period are depicted.

\subsection{Rainfall comparison}

In this section, the skill of the PERSIANN rainfall products to replicate the variability of rainfall amounts and occurrence as measured by in situ rain gauges within the VAS site is investigated for 2006 and 2007. Figure 2 presents comparisons of monthly rainfall estimates between all 22 meteorological stations within the $50 \times 50 \mathrm{~km}^{2}$ VAS area and their nearest PERSIANN points (PP). Although there is a general agreement in rainfall patterns, the precipitation values produced by PERSIANN substantially overestimate the 

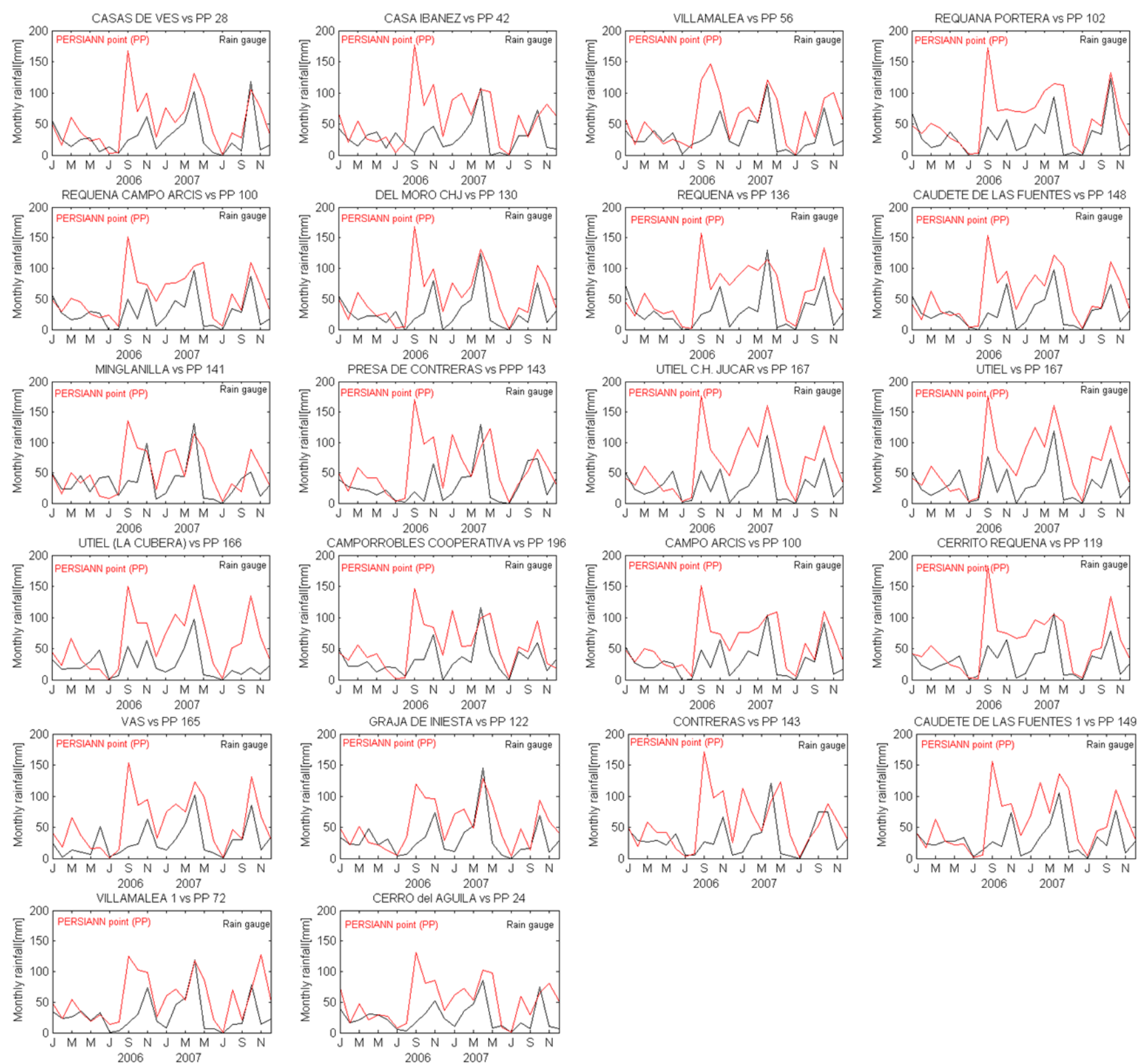

Fig. 2. Monthly comparisons between all the meteorological stations/rain gauges (black line) within the $50 \times 50 \mathrm{~km}^{2}$ VAS area and their nearest PERSIANN points (red lines) for 2006 and 2007.

rainfall amounts in comparison with the gauges. This overestimation is clearly more distinct in the winter months than in the summer months, and most extreme in September 2006, where the rain gauges record rainfall amounts smaller than $50 \mathrm{~mm} /$ month whereas the PERSIANN products systematically exceeds $150 \mathrm{~mm} /$ month. The same pattern is observed in January and February 2007, though to a less pronounced extent. Table 1 lists both the root-mean square error (RMSE) and the mean bias (Mbias) of daily precipitation between each corresponding in situ rainfall observation and
PERSIANN point for the entire VAS site for the years 2006 and 2007. It shows that the deviation between the rain gauge measurements and the PERSIANN product remains spatially and temporally consistent in most of the considered cases. Table 2 shows the differences in terms of rainfall occurrence (number of detected rain events) between all meteorological stations/rain gauges available within the VAS area and their nearest PERSIANN point for the years 2006 and 2007 at a daily scale. In most cases the PERSIANN points show at least twice the number of rainfall events than the rain gauges. 
Table 1. List of all the meteorological stations/ rain gauges (1st column) and their nearest PERSIANN points (2nd column) available over the VAS area. The root-mean square error (RMSE) and the mean bias (Mbias) of daily precipitation between each in situ rainfall observation and PERSIANN point are calculated for 2006 and 2007.

\begin{tabular}{llllll}
\hline Station Name & $\begin{array}{l}\text { PERSIANN } \\
\text { point }\end{array}$ & $\begin{array}{l}2006 \\
\text { RMSE } \\
\text { mm/day }\end{array}$ & $\begin{array}{l}\text { Mbias } \\
\text { mm/day }\end{array}$ & $\begin{array}{l}2007 \\
\text { RMSE } \\
\text { mm/day }\end{array}$ & $\begin{array}{l}\text { Mbias } \\
\text { mm/day }\end{array}$ \\
\hline CASAS DE VES & 28 & 5.69 & 0.80 & 6.04 & 0.90 \\
CASAS IBANEZ & 42 & 6.96 & 0.90 & 6.95 & 1.11 \\
VILLAMALEA & 56 & 6.13 & 0.77 & 6.57 & 1.02 \\
REQUENA LA PORTERA COOP. & 102 & 6.04 & 0.82 & 6.43 & 1.11 \\
REQUENA CAMPO ARCIS & 100 & 4.79 & 0.77 & 5.82 & 1.06 \\
DEL MORO CHJ & 130 & 5.82 & 0.76 & 5.92 & 0.94 \\
REQUENA & 136 & 5.31 & 0.81 & 6.31 & 1.19 \\
CAUDETE DE LAS FUENTES & 148 & 5.58 & 0.73 & 5.95 & 1.03 \\
MINGLANILLA & 141 & 5.70 & 0.34 & 5.98 & 0.79 \\
PRESA DE CONTRERAS & 143 & 6.15 & 1.08 & 6.72 & 0.76 \\
UTIEL CHJ & 167 & 5.83 & 0.76 & 6.92 & 1.59 \\
UTIEL & 167 & 6.03 & 0.69 & 6.93 & 1.55 \\
UTIEL (LA CUBERA) & 166 & 5.61 & 0.71 & 6.38 & 1.69 \\
CAMPORROBLES COOPERATIVA & 196 & 5.86 & 0.75 & 5.53 & 0.70 \\
CAMPO ARCIS & 100 & 4.75 & 0.77 & 5.22 & 1.00 \\
CERRITO REQUENA & 119 & 5.55 & 0.78 & 5.53 & 1.08 \\
VAS & 165 & 5.71 & 0.91 & 5.26 & 1.02 \\
GRAJA DE INIESTA & 122 & 4.54 & 0.62 & 5.43 & 0.80 \\
CONTRERAS & 143 & 6.03 & 0.86 & 6.53 & 0.82 \\
CAUDETE DE LAS FUENTES 1 & 149 & 5.52 & 0.68 & 5.93 & 1.23 \\
VILLAMALEA 1 & 72 & 4.80 & 0.75 & 6.20 & 1.01 \\
CERRO & 24 & 4.87 & 0.76 & 5.48 & 1.01 \\
\hline
\end{tabular}

In order to investigate the spatial and temporal variability of the PERSIANN product, a more in-depth comparison between a representative rain gauge called Caudete de las Fuentes 1 (CA FU1) and its 9 neighbouring PERSIANN points (PP) was conducted on a daily basis. Figure 3 depicts the location of the selected rain gauge and the surrounding PERSIANN points, while Table 3 summarizes the differences in daily rainfall amounts in terms of RMSE and Mbias for the years 2006 and 2007. Again, substantial differences in terms of range are observed and in terms of spatial variability an homogeneous rainfall distribution is encountered around the CA FU1 point. In general, PERSIANN overestimates rainfall compared to the gauges, especially in the rainy seasons, which was also found over India by Brown (2006) and across Australia, the Pacific, parts of Asia by Sorooshian et al. (2000). The most significant difference in rainfall amount between CA FU1 and its surrounding PERSIANN points is again observed in September 2006 - while the CA FU1 rain gauge records only a slight amount of rainfall all the PERSIANN points (PP) show rainy events beyond $20 \mathrm{~mm} /$ day. During the summer season, the rain gauge and the PERSIANN points show better agreement with CA FU1 rainfall amounts around $45 \mathrm{~mm} /$ day and rainfall amounts of the PERSIANN points of about $70 \mathrm{~mm} /$ day in the months of

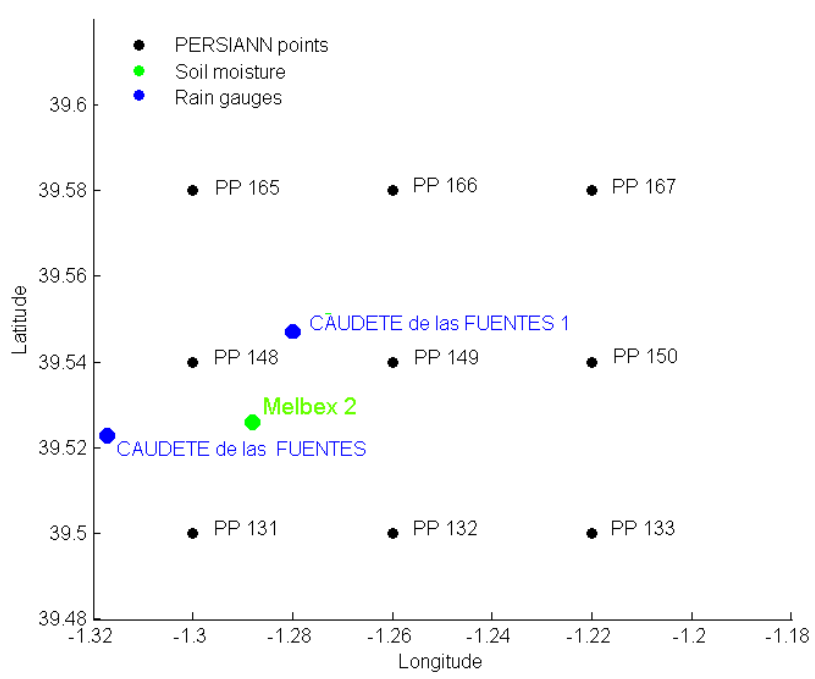

Fig. 3. Positions of Caudete de las Fuentes (CA FU) and Caudete de las Fuentes 1 rain gauges (blue dots), PERSIANN neighboring points (black dots with number of reference), and the Melbex 2 soil moisture campaign site (green dot). 
Table 2. Contingency table illustrating the number of rain events measured by the satellite but not measured by the rain gauges and vice versa (R stands for "rain" and NR stands for "non rain"). The comparison was done between all the meteorological stations/ rain gauges and their nearest PERSIANN points available over the VAS area for 2006 and 2007.

\begin{tabular}{|c|c|c|c|c|c|c|c|c|}
\hline \multirow{2}{*}{ Station Name/PERSIANN point } & \multicolumn{4}{|l|}{2006} & \multicolumn{4}{|l|}{2007} \\
\hline & $\mathrm{R} / \mathrm{R}$ & $\mathrm{R} / \mathrm{NR}$ & $N R / R$ & NR/NR & $\mathrm{R} / \mathrm{R}$ & $\mathrm{R} / \mathrm{NR}$ & $N R / R$ & NR/NR \\
\hline CASAS DE VES / PP 28 & 63 & 44 & 51 & 208 & 75 & 45 & 40 & 205 \\
\hline CASA IBANEZ / PP 42 & 21 & 19 & 86 & 240 & 26 & 11 & 83 & 245 \\
\hline VILLAMALEA / PP 56 & 38 & 28 & 71 & 229 & 48 & 12 & 60 & 245 \\
\hline REQUANA PORTERA / PP 102 & 17 & 10 & 96 & 243 & 19 & 7 & 85 & 254 \\
\hline REQUENA CAMPO ARCIS / PP 100 & 39 & 23 & 71 & 233 & 37 & 17 & 67 & 244 \\
\hline DEL MORO CHJ / PP 130 & 30 & 12 & 84 & 240 & 34 & 3 & 81 & 247 \\
\hline REQUENA / PP 136 & 35 & 20 & 84 & 227 & 39 & 7 & 74 & 245 \\
\hline CAUDETE DE LAS FUENTES / PP 148 & 26 & 11 & 90 & 239 & 35 & 5 & 78 & 247 \\
\hline MINGLANILLA / PP 141 & 33 & 17 & 78 & 238 & 34 & 8 & 74 & 249 \\
\hline PRESA DE CONTRERAS / PP 143 & 44 & 33 & 69 & 220 & 50 & 23 & 67 & 225 \\
\hline UTIEL C.H.J. / PP 167 & 38 & 21 & 81 & 226 & 36 & 9 & 79 & 241 \\
\hline UTIEL / PP 167 & 36 & 17 & 83 & 230 & 38 & 5 & 77 & 245 \\
\hline UTIEL (LA CUBERA) / PP 166 & 51 & 44 & 66 & 205 & 51 & 42 & 64 & 208 \\
\hline CAMPORROBLES COOPERATIVA / PP 196 & 30 & 13 & 84 & 239 & 31 & 6 & 77 & 251 \\
\hline CAMPO ARCIS / PP 100 & 56 & 52 & 54 & 204 & 45 & 56 & 59 & 205 \\
\hline CERRITO REQUENA / PP 119 & 54 & 47 & 63 & 202 & 57 & 37 & 49 & 222 \\
\hline VAS / PP 165 & 38 & 41 & 78 & 209 & 62 & 60 & 53 & 190 \\
\hline GRAJA DE INIESTA / PP 122 & 52 & 38 & 69 & 207 & 55 & 24 & 58 & 228 \\
\hline CONTRERAS / PP 143 & 49 & 41 & 64 & 212 & 53 & 33 & 64 & 215 \\
\hline CAUDETE DE LAS FUENTES 1 / PP 149 & 51 & 46 & 68 & 201 & 52 & 26 & 62 & 225 \\
\hline VILLAMALEA 1 / PP 72 & 45 & 40 & 58 & 223 & 57 & 25 & 53 & 230 \\
\hline CERRO / PP 24 & 46 & 40 & 58 & 222 & 47 & 32 & 68 & 218 \\
\hline
\end{tabular}

Table 3. Statistical analysis between Caudete de las Fuentes1 (CA FU1) rain gauge and of its nine PERSIANN neighbours (PP) for 2006 and 2007.

\begin{tabular}{lllll}
\hline Rain gauge CA FU1/PERSIANN point & $\begin{array}{l}2006 \\
\text { RMSE } \\
\text { mm/day }\end{array}$ & $\begin{array}{l}\text { Mbias } \\
\mathrm{mm} / \text { day }\end{array}$ & $\begin{array}{l}2007 \\
\text { RMSE } \\
\mathrm{mm} / \text { day }\end{array}$ & $\begin{array}{l}\text { Mbias } \\
\mathrm{mm} / \text { day }\end{array}$ \\
\hline CA FU1/PP131 & 5.64 & 0.71 & 5.19 & 1.02 \\
CA FU1/PP132 & 5.44 & 0.69 & 5.70 & 1.06 \\
CA FU1/PP133 & 5.79 & 0.84 & 5.79 & 1.25 \\
CA FU1/PP148 & 5.60 & 0.69 & 5.36 & 1.04 \\
CA FU1/PP149 & 5.53 & 0.68 & 5.93 & 1.24 \\
CA FU1/PP150 & 5.61 & 0.74 & 6.35 & 1.45 \\
CA FU1/PP165 & 5.66 & 0.71 & 5.31 & 1.09 \\
CA FU1/PP166 & 5.62 & 0.74 & 6.12 & 1.35 \\
CA FU1/PP167 & 5.64 & 0.79 & 6.42 & 1.61 \\
\hline
\end{tabular}

June, July and August (2006 and 2007). The fact that the satellite data represents areal rainfall, while the gauge data represents point rainfall can also induce precipitation differences. In order to test this, rainfall amounts of one grid cell of the interpolated $10 \times 10 \mathrm{~km}^{2}$ rainfall grid derived from all in situ observations within VAS are compared with rainfall estimates at each of the 12 PERSIANN points located within this cell as well as with the spatial mean of all 12 PERSIANN points. The analysis is done for 2007 at a daily scale, and results are presented in Fig. 4. It shows that a slight improvement in terms of RMSE and correlation $\left(R^{2}\right)$ is obtained when comparing data at the same spatial scale: while no correlation is observed between the interpolated rainfall and each nearest PP individually and the RMSE value is above $6.73 \mathrm{~mm} /$ day in most cases, the comparison between the spatial mean of the $12 \mathrm{PP}$ and the interpolated rainfall reveals 

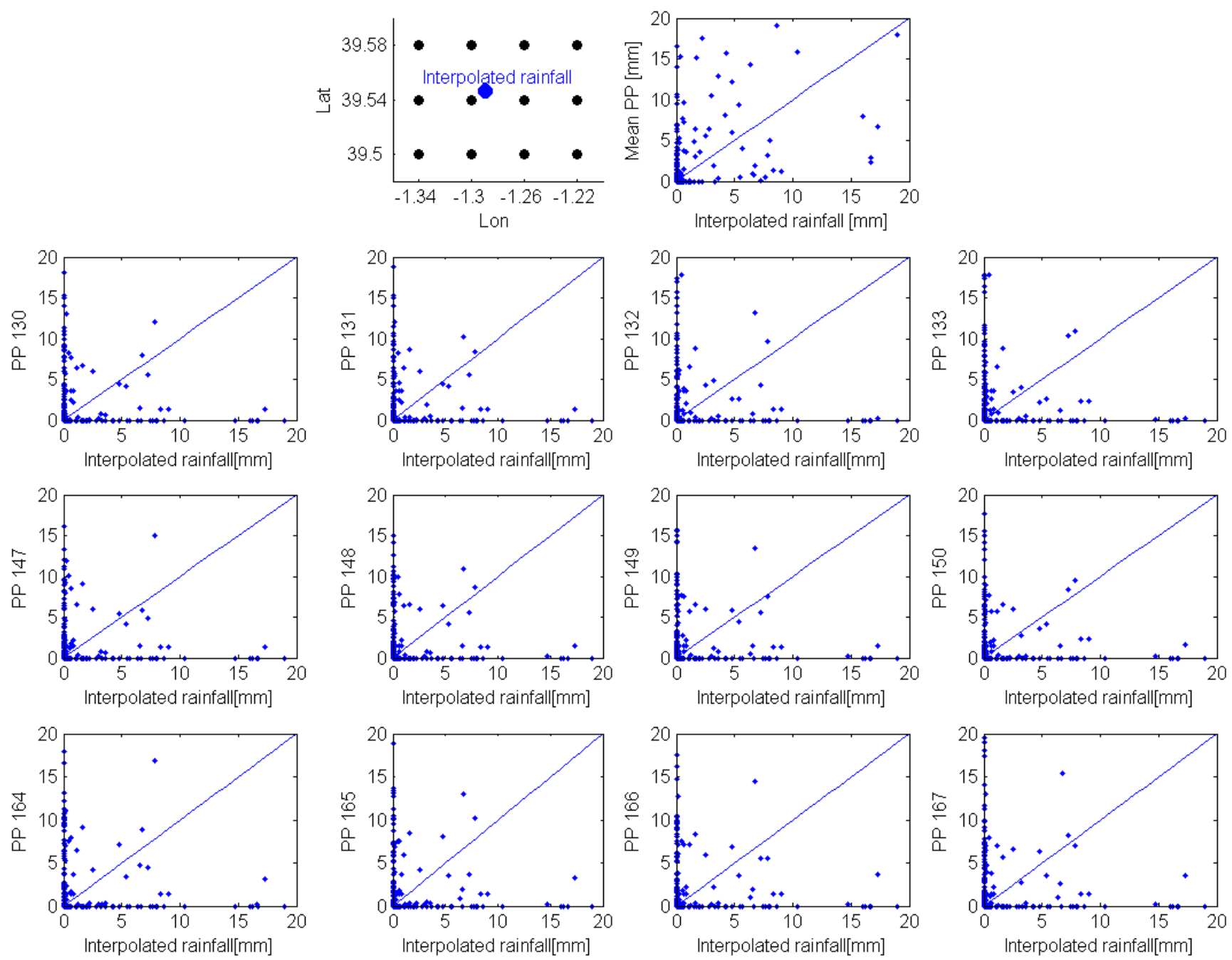

Fig. 4. Comparison between interpolated rainfall product ( $x$-axis) and PERSIANN points ( $y$-axis). The interpolated rainfall is representative over a $10 \times 10 \mathrm{~km}^{2}$ area and is obtained using in situ observations over VAS. The mean PP represents the spatial average of the 12 PERSIANN points available within the same grid as the interpolated rainfall. The top left figure provides a map (longitude $x$-axis, latitude $y$-axis) representing the interpolated rainfall and the PERSIANN points, while the top right figure represents the comparison between the interpolated rainfall and the PERSIANN mean. The 2nd, 3rd and 4th rows present comparisons of the interpolated rainfall ( $x$-axis) and each PERSIANN point ( $y$-axis). The analysis is done for 2007 at a daily scale.

an $R^{2}$ of $0.23-/-$ and an RMSE of about $5.32 \mathrm{~mm} /$ day. Figure 5 finally shows a comparison of the daily rainfall rates (2006 and 2007) of the rain gauges CA FU1 and CA FU which are located about $4 \mathrm{~km}$ apart (see Fig. 3). Despite their proximity, the recorded rainfall at the two stations for 2006 is not highly correlated $\left(R^{2}=0.36-/-\right)$. This low correlation indicates a high small-scale spatial rainfall variability over the VAS area, and demonstrates that the missing correlation between rain gauges and PPs - not exactly located at the same points - could at least partly be explained by this phenomenon. However, most likely the issue of comparing point rain gauge data with spatialized PERSIANN rainfall estimates also contributes to the disagreement of the two datasets. This is underlined by the fact that the correlation is improved when comparing the two datasets at the same spatial scale, clearly highlighting the importance of scaling issues. The still existing discrepancy could for example be caused by uncertainty in the spatialized rainfall estimate from in situ data introduced through interpolation of the sparse and irregularly distributed rain gauge data, which further emphasizes the high importance of the scaling problem when comparing datasets. Another explanation for the remaining disagreement between the two datasets even when compared at equal spatial scale could also be the fact that 

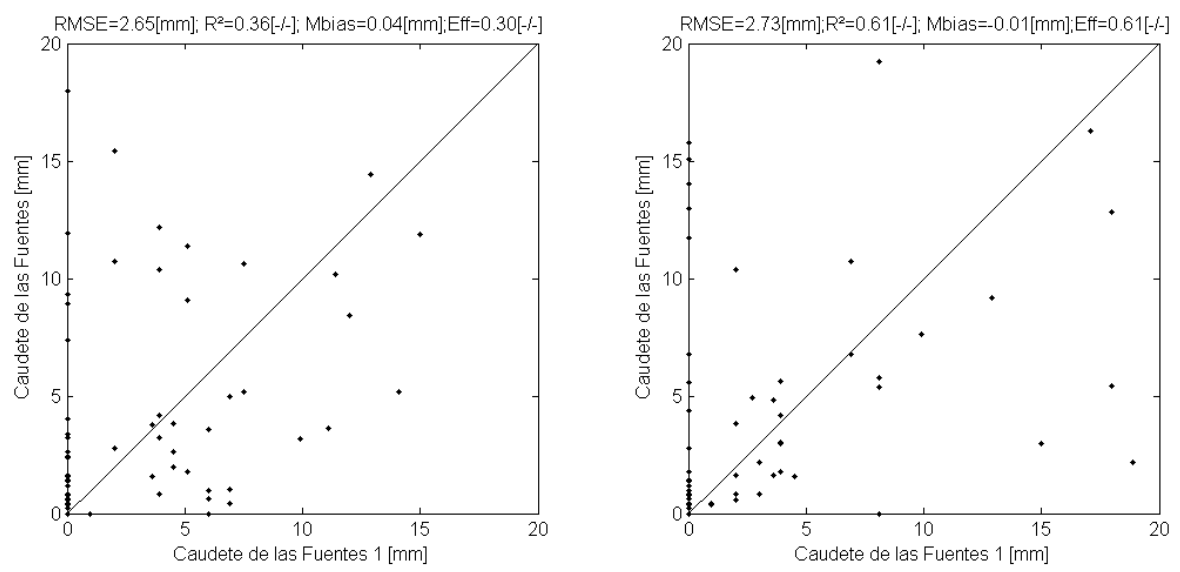

Fig. 5. Precipitation events at Caudete de las Fuentes ( $y$-axis) versus Caudete de las Fuentes 1 ( $x$-axis) rain gauges for 2006 (left hand figure) and 2007 (right hand figure). See Fig. 3 for gauge positions.

the PERSIANN system does not involve local calibration in producing its rainfall estimates. It is suggested that the product could be improved through calibration by means of in situ observations. Finally, the rain gauge measurements are quite error-prone as well through shelter effects/undercatch and sometimes are very difficult to access in a timely fashion to drive a model. These issues has to be considered as they can induce additional uncertainties.

\subsection{Soil moisture}

\subsubsection{Point to point comparison between soil moisture data}

The objective of this comparison is to assess whether the satellite data can be used instead of gauge data as inputs to a hydrological model. For the point scale soil moisture simulations the SVAT model was driven by precipitation input from three different point datasets, namely from the CA FU and CA FU1 rain gauges and the PERSIANN point PP148. The simulated soil moisture and in situ point soil moisture measurements recorded during the Melbex 2 campaign were compared at an hourly scale from June to December 2007. The comparisons were conducted over the top $5 \mathrm{~cm}$ of soil and are illustrated in Fig. 6. Results indicate that there is a considerable impact on soil moisture when using different precipitation forcing for the SVAT simulations. All three simulations show deviations from the observed in situ soil moisture with RMSE values ranging from $0.02 \mathrm{~m}^{3} \mathrm{~m}^{-3}$ for CA FU1 to $0.06 \mathrm{~m}^{3} \mathrm{~m}^{-3}$ for CA FU and PP148, though with considerably different patterns. The CA FU1 simulation follows the observed soil moisture trend most closely over the entire studied time interval. Meanwhile the CA FU simulation generally depicts dryer soil moisture values than the measured ones. This can be explained by the observed rainfall patterns at the two different gauge stations. While the total rainfall amounts recorded for the entire period are in comparable range with $189.85 \mathrm{~mm}$ and $172.08 \mathrm{~mm}$ at CA FU and CA FU1, respectively, the precipitation occurrence registered at CA FU is more widely spread in time, causing a longer period of dry soil moisture values. The PP148 runs indicate generally a much wetter soil than the measured one, especially in the second half of the investigated time period. This pattern is consistent with the overestimation of late fall and winter precipitation by the satellite products. A total rainfall amount of $314.12 \mathrm{~mm}$ within the considered period is encountered in the PERSIANN data, almost twice than the total rain gauge amounts.

Figure 7 shows a more detailed comparison of soil moisture simulated with the three different precipitation inputs at the top $5 \mathrm{~cm}$ of the soil at an hourly time step for the years 2006 and 2007. The statistical analysis of the comparison is summarized in Table 4 . The analysis indicates a wide range of accuracies with a noticeable season-dependency. As in the case of rainfall amounts largest disagreements are generally observed during the late fall and early winter seasons. When soil moisture simulated by means of CA FU 1 and CA FU rainfall records is compared with soil moisture estimated from PP148 data for the year 2006, RMSE values of $0.07 \mathrm{~m}^{3} \mathrm{~m}^{-3}$ and $0.06 \mathrm{~m}^{3} \mathrm{~m}^{-3}$ are obtained, respectively. When only considering the period from January to the end of August 2006 a notable improvement of the results is observed with RMSE values of $0.037 \mathrm{~m}^{3} \mathrm{~m}^{-3}$ for both comparisons, CA FU/PP148 and CA FU1/ PP148. The correlation values $\left(R^{2}\right)$ are also better, reaching values of 0.70 $-/-$ and $0.64-/-$ for the period from January to August 2006 compared to $0.52-/-$ and $0.50-/-$ for the entire year 2006 in case of CA FU/ PP148 and CA FU1/ PP148, respectively. To better understand these discrepancies obtained at the end of the year, a more detailed analysis is done for September 2006 (day of year 244 to 273). For the PP148 

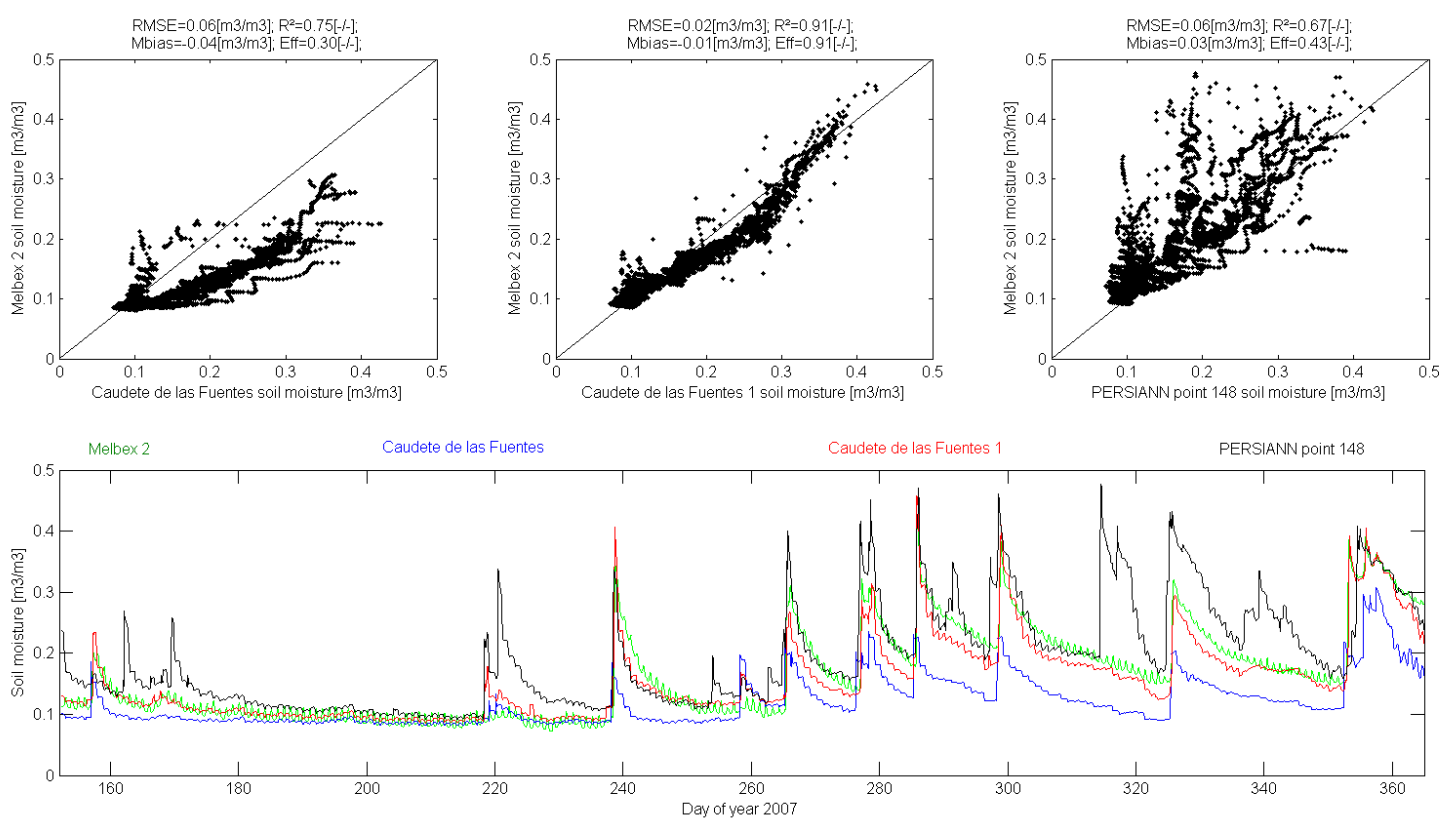

Fig. 6. Simulated soil moisture integrated over top $5 \mathrm{~cm}$ of soil using Caudete de las Fuentes rain gauge, Caudete de las Fuentes 1 rain gauge and the PERSIANN point 148 compared to Melbex 2 in situ soil moisture from 1 June to 31 December 2007.

Table 4. Statistical analysis between simulated point soil moisture integrated over the top $5 \mathrm{~cm}$ of soil using Caudete de las Fuentes (CA FU), Caudete de las Fuentes1 (CA FU1) and the PERSIANN point PP148 for 2006 and 2007.

\begin{tabular}{llccc}
\hline & & CA FU/PP148 & CA FU1/ PP148 & CA FU1/CA FU \\
\hline 2006 & RMSE $\mathrm{m}^{3} \mathrm{~m}^{-3}$ & 0.07 & 0.06 & 0.03 \\
& $R^{2}-/-$ & 0.52 & 0.50 & 0.87 \\
& Mbias m $\mathrm{m}^{-3}$ & 0.04 & 0.02 & -0.02 \\
& Eff $-/-$ & -0.92 & 0.01 & 0.74 \\
\hline 2007 & RMSE $\mathrm{m}^{3} \mathrm{~m}^{-3}$ & 0.09 & 0.06 & 0.05 \\
& $R^{2}-/-$ & 0.54 & 0.62 & 0.81 \\
& Mbias m $\mathrm{m}^{3}$ & 0.07 & 0.04 & -0.04 \\
& Eff $-/-$ & -2.26 & 0.18 & 0.50 \\
\hline
\end{tabular}

simulation a monthly precipitation average of $5.30 \mathrm{~mm} /$ day results in a monthly soil moisture mean of $0.20 \mathrm{~m}^{3} \mathrm{~m}^{-3}$, while in the case of the two rain gauge model runs a monthly precipitation average of $0.89 \mathrm{~mm} /$ day results in a monthly soil moisture mean of $0.12 \mathrm{~m}^{3} \mathrm{~m}^{-3}$. From September to December 2006 RMSE of $0.10 \mathrm{~m}^{3} \mathrm{~m}^{-3}$ and $0.11 \mathrm{~m}^{3} \mathrm{~m}^{-3}$ and correlation values of $0.46-1-$ and $0.40-/-$ are found for CA FU1/PP148 and CA FU/ PP148. For 2007, the difference in simulated soil moisture between the PP148 and rain gauge model runs is slightly higher than for 2006. However, from September to December 2007, the impact of the precipitation is less significant than for 2006, with RMSE of $0.07 \mathrm{~m}^{3} \mathrm{~m}^{-3}$ and $0.11 \mathrm{~m}^{3} \mathrm{~m}^{-3}$ and correlation values of
0.53 - / - and $0.40-/-$ for CA FU1/ PP148 and CA FU/ PP148, respectively. It is most likely that the discrepancies in soil moisture obtained by means of the three different rainfall input datasets are associated with the observed differences in rainfall estimates between the gauges and PERSIANN satellite data as shown in the previous section. We conclude that one of the factors responsible for these deviations could be the scale issue between the areal satellite data and the gauge point measurements. However, the differences in soil moisture are much lesser than the differences in precipitation forcing. Thus, in the following section results of the comparison of products at equivalent scale representative for the $50 \times 50 \mathrm{~km}^{2}$ VAS site are presented. 

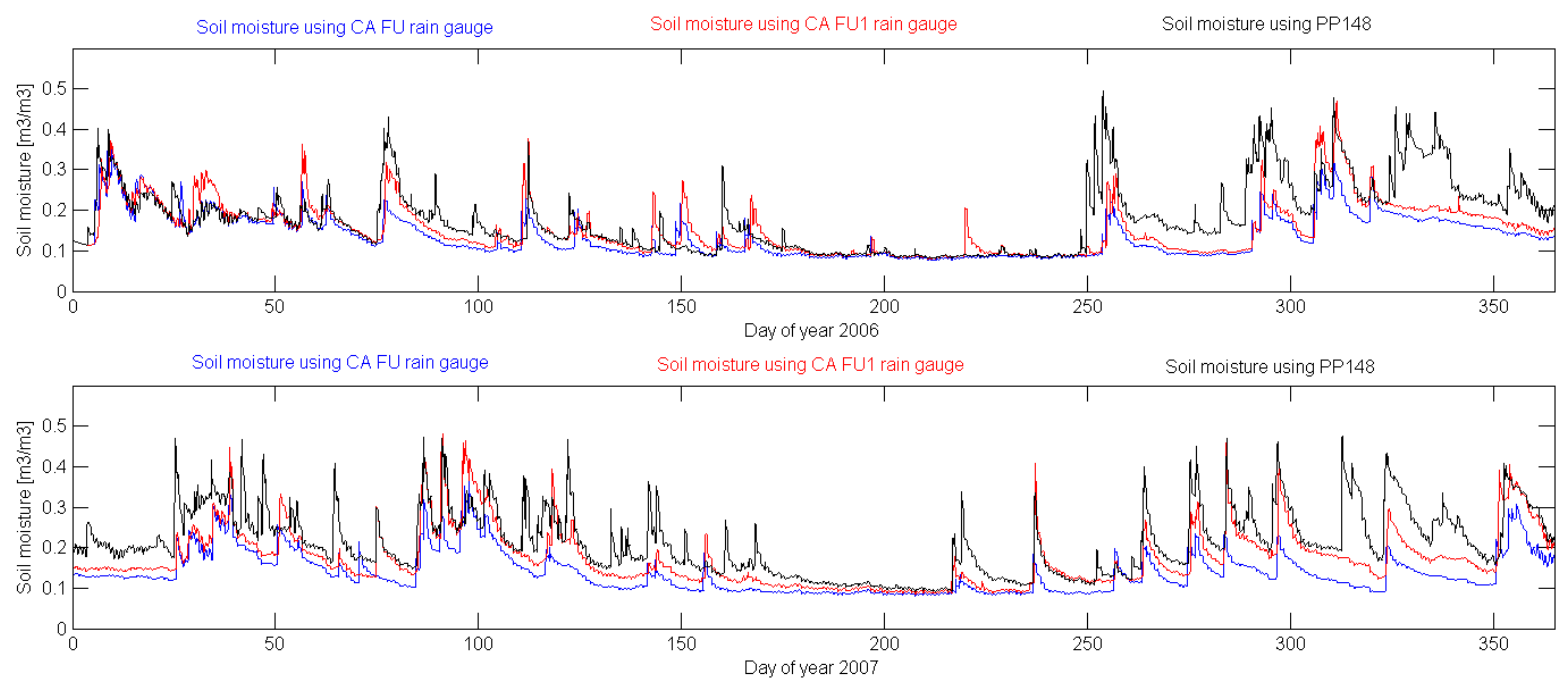

Fig. 7. Comparison between simulated soil moisture integrated over top $5 \mathrm{~cm}$ of soil using Caudete de las Fuentes rain gauge (blue line), Caudete de las Fuentes 1 rain gauge (red line) and the PERSIANN point PP148 (black line). The comparison is made for 2006 (upper figure) and 2007 (bottom figure).
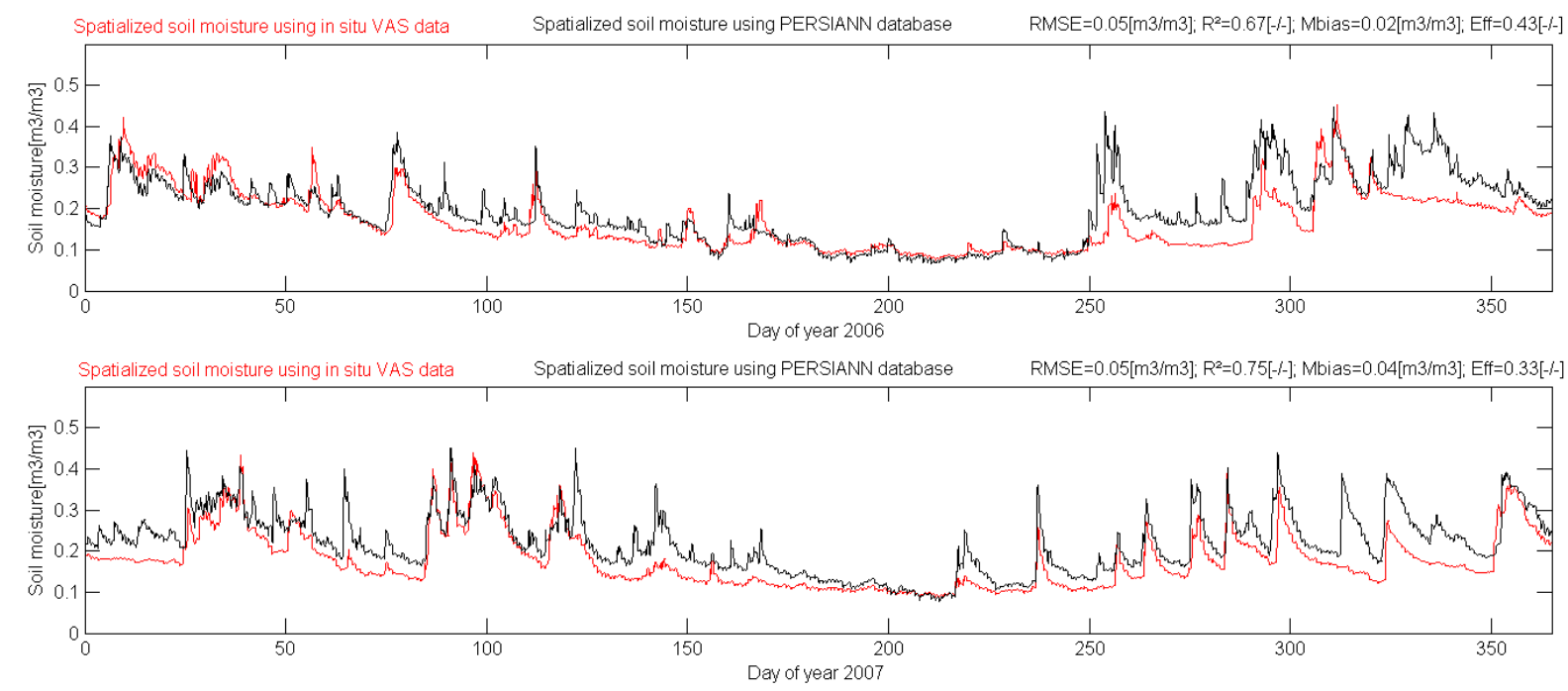

Fig. 8. Comparison between spatialized soil moisture databases obtained using in situ rain gauge observations from VAS area (red line) and the PERSIANN satellite rainfall estimates (black line) for 2006 (upper figure) and 2007 (bottom figure).

\subsubsection{Spatialized soil moisture over VAS area}

The average values of the two spatialized soil moisture simulations of the top $5 \mathrm{~cm}$ of soil over the VAS site are compared: one spatialized soil moisture (VAS) obtained using the gauge data combined through an areal interpolation approach (IDW) and another spatialized soil moisture data (PERSIANN) obtained using the satellite rainfall estimates. The comparison between both data is made for 2006 and 2007 on a daily basis. Results are presented in Fig. 8 . Amplitude and variation of the two simulated soil moisture datasets remain similar throughout the two investigated years. In 2006 a good statistical agreement between the two datasets with RMSE of $0.03 \mathrm{~m}^{3} \mathrm{~m}^{-3}$ and $R^{2}$ of $0.83-/-$ is maintained from the beginning of the year until the end of the summer. Dividing this time span into two shorter intervals reveals an RMSE of $0.03 \mathrm{~m}^{3} \mathrm{~m}^{-3}$ and $R^{2}$ of $0.74-/-$ from January to May, and an even lower RMSE of $0.01 \mathrm{~m}^{3} \mathrm{~m}^{-3}$ 
Table 5. Statistical analysis between SM VAS (spatialized soil moisture obtained using in situ observations), SM PERSIANN (spatialized soil moisture data obtained using PERSIANN satellite rainfall estimates), SM AMSR-E (AMSR-E soil moisture product) and PR AMSR-E (AMSR-E polarization ratio $6.9 \mathrm{GHz}$ ) for 2006 and 2007.

\begin{tabular}{llcc}
\hline & & RMSE $-/-$ & $R^{2}-l-$ \\
\hline \multirow{2}{*}{2006} & SM VAS/SM AMSR-E & 0.24 & 0.07 \\
& SM PERSIANN/SM AMSR-E & 0.26 & 0.01 \\
& SM VAS/PR AMSR-E 6.9 GHz & 0.17 & 0.50 \\
& SM PERSIANN/PR AMSR-E 6.9 GHz & 0.17 & 0.41 \\
\hline \multirow{2}{*}{2007} & SM VAS/SM AMSR-E & 0.19 & 0.38 \\
& SM PERSIANN/SM AMSR-E & 0.20 & 0.24 \\
& SM VAS/PR AMSR-E 6.9 GHz & 0.13 & 0.67 \\
& SM PERSIANN/PR AMSR-E 6.9 GHz & 0.14 & 0.53 \\
\hline
\end{tabular}

though with an also lower $R^{2}$ of $0.60-/-$ from June to August. From September until the end of the year the RMSE increases to $0.08 \mathrm{~m}^{3} \mathrm{~m}^{-3}$ while $R^{2}$ is lowered to $0.56-/-$. In 2007 RMSE and $R^{2}$ values are $0.06 \mathrm{~m}^{3} \mathrm{~m}^{-3}$ and $0.68-/-$ from January to May, $0.04 \mathrm{~m}^{3} \mathrm{~m}^{-3}$ and $0.82-1-$ from June to August, and $0.06 \mathrm{~m}^{3} \mathrm{~m}^{-3}$ and $0.65-/-$ from September to December, respectively. The discrepancy between the two datasets is in comparable range for the two years, only at the end of the year it is slightly smaller in the year 2007, indicating that less error is introduced in the simulated soil moisture. While point to point comparisons between soil moisture data are influenced by the high small-scale variability of rainfall events and occurrence, the use of spatialized data (average of several simulated grid points) attenuates these influences, leading to more consistent soil moisture results.

\subsubsection{Comparison with AMSR-E data}

The average values of the two spatialized soil moisture datasets (VAS and PERSIANN) representative for the $50 \times 50 \mathrm{~km}^{2}$ VAS site were compared with the soil moisture product (Njoku L3) and the polarization ratio at $6.7 \mathrm{GHz}$ derived from remotely sensed AMSR-E data for the years 2006 and 2007. As the penetration depth of AMSR-E is approximately $2 \mathrm{~cm}$, the simulated soil moisture integrated over the first $2 \mathrm{~cm}$ depth is considered, and since the AMSR-E soil moisture product shows biases and very small amplitudes (Rüdiger et al., 2009; Gruhier et al., 2010), the simulated soil moisture datasets and the AMSR-E data are normalized between $[0,1]$. Results are shown in Fig. 9 and summarized in Table 5. All presented statistics are calculated for the normalized soil moisture values and are therefore dimensionless. In general we can observe that the dynamics of the soil moisture are well captured by the simulated data for both 2006 and 2007. In the beginning of both years, the AMSR-E products and average spatialized soil moisture simulations are in comparable range. In the middle of the year the AMSR-E soil moisture product shows only low correlations with the rain gauge and PERSIANN datasets. This can be explained by the perturbance of the AMSR-E signal by the growing vegetation. However, the spatialized soil moisture products are found to be in better agreement with the polarization ratio. While significant deviations between the AMSR-E soil moisture product and the simulated data commence around day of year (DOY) 100/120 for 2006/2007, respectively, in case of the polarization ratio the drift starts only around DOY $150 / 190$ and with a much smaller amplitude. This shows that the sensitivity of the polarization ratio to vegetation becomes significant at a remarkably later stage in the growing period where larger amounts of vegetation biomass are present on the ground for which reason the polarization ratio represents the dynamic behaviour of the soil moisture content much better than the AMSR-E soil moisture product. This is underlined by the correlation coefficients which are significantly higher between the simulated datasets VAS and PERSIANN and the polarization ratio than between simulated datasets and the AMSR-E soil moisture product for both years with values in the range from $0.41-/-$ to $0.67-/-$ and from 0.01 $-/-$ to $0.38-/-$, respectively. Around DOY 200/230 the AMSR-E soil moisture and polarization radio level at a significantly higher value than the two simulated soil moisture estimates, while from around DOY 290 to $320 / 290$ to 340 the AMSR-E products follow the simulations more closely again. From that point on there is again good agreement between the VAS simulation and the polarization ratio (and also the AMSR-E soil moisture in 2007), while the high soil moisture values of the PERSIANN simulation induced by rainfall overestimation of the satellite product are clearly standing out in both years. The fact that the simulated datasets and the polarization ratio compare well during the spring and summer seasons (apart from late summer/early autumn with full-grown vegetation) in both 2006 and 2007 is important because it shows that although the PERSIANN products overestimate the total rainfall during the year, during this period precipitation seems to be accurately represented by these satellite estimates. 

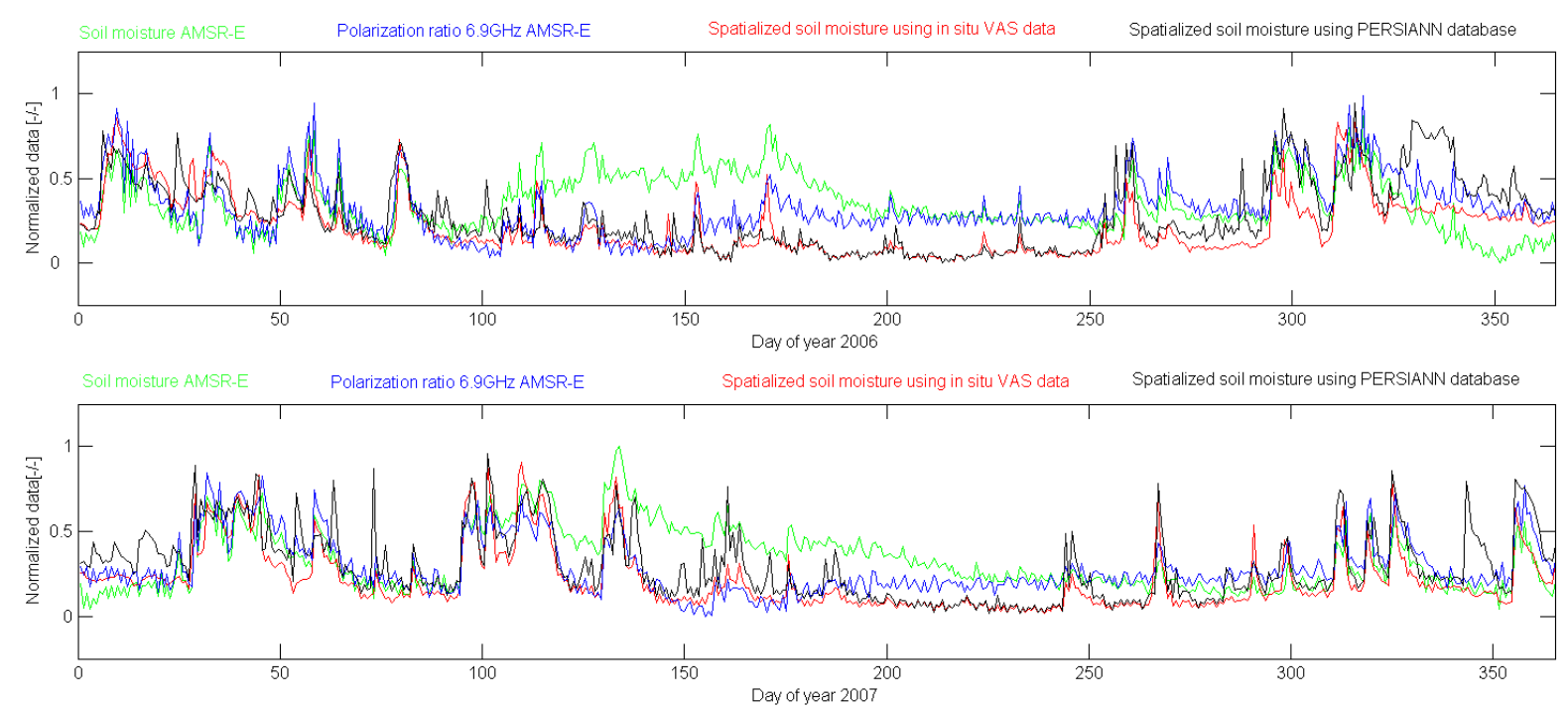

Fig. 9. Comparison between spatialized soil moisture using in situ rain gauge observations(red line) and PERSIANN datadase (black line), AMSR-E soil moisture product (green line) and AMSR-E polarization ratio at $6.9 \mathrm{GHz}$ (blue line) for 2006 (upper figure) and 2007 (bottom figure). The data are normalized between $[0,1]$.

\section{Conclusions}

In the framework of Calibration and Validation activities of the Soil Moisture and Ocean Salinity (SMOS) mission, obtaining a brightness temperature comparable with the instrument measurements is an important issue. For that purpose a good knowledge of soil moisture over a large area is necessary as the spatial resolution of SMOS is in the order of $50 \times 50 \mathrm{~km}^{2}$. SVAT models can be used to simulate soil moisture fields over such large areas. However, they require input data at the same scale, amongst others precipitation data. Precipitation amounts and occurrence are considered as an important factor in controlling spatial and temporal patterns of the soil moisture. Due to its high variability in space and time as well as its highly intermittent occurrence, measuring precipitation requires dense spatial sampling to achieve a good accuracy. This study is performed over the Valencia Anchor Station (2006-2007) which provides in situ data at large scale. Meanwhile, the sparse distribution of the rain gauges within the area can be a limit to our approach. In this context, this paper investigates the benefit of applying the PERSIANN database to reproduce the high temporal and spatial heterogeneity of soil moisture fields at SMOS pixel scale compared to using sparsely and irregularly distributed in situ rain gauge measurements. An evaluation of PERSIANN rainfall amount and occurrence was undertaken. Local meteorological station/gauge data and the PERSIANN estimates do not compare very well. During the summer season, when the precipitation occurrence and amounts are less important, patterns in rainfall are better reproduced. How- ever, during late fall and winter substantial differences between the different rainfall data in terms of range and temporal variability are observed. This can be explained by the small-scale variability of the rainfall over the VAS region as well as by the scale difference of the databases. Whereas rain gauges record the rainfall at a point, the PERSIANN satellite estimates integrate the amount of rain over a wider area. Although important local differences exist, averages at equivalent scale show results in better agreement. Used as input to a SVAT model - ISBA - the PERSIANN product has an important impact when it is used in point-like modeling. However, the differences in soil moisture are much lesser than the differences in precipitation forcing. Nevertheless, there are periods (late fall and winter) when the soil moisture differences are of equivalent magnitude to that of the precipitation forcing. A wide range of accuracies when comparing several soil moisture data obtained using different precipitation estimates is observed. These differences depend on the season, being marked especially at the end of the year, when, as in the case of the rainfall, an important disagreement is observed. Two spatialized soil moisture information representative over the $50 \times 50 \mathrm{~km}^{2}$ are obtained using ISBA coupled to a set of forcings and a good knowledge of soil types and land use. One spatialized soil moisture is obtained using the gauge data combined through an areal interpolation approach (IDW) and another spatialized soil moisture data obtained using PERSIANN satellite rainfall estimates. The simulated soil moisture using satellite estimates generally performs well, both amplitude and variation being retrieved. However, at the end of the year 
(from September), when the precipitation amounts are the most different, the RMSE value is higher than the rest of the year. This spatialized approach significantly improves the results. To check the validity of both spatialized soil moisture data, a comparison with AMSR-E product is performed. Due to several launching delays SMOS data was not available at the point this study was conducted. Although AMSR-E surface soil moisture product is not able to capture the absolute value, it provides reliable information on surface soil moisture temporal variability, at seasonal and rainy events scale. In general we can observe that the dynamics of the soil moisture are well captured during the whole year by both spatialized soil moisture databases (VAS and PERSIANN). From April to September, during the vegetation growing season the AMSR-E signal is very perturbed inducing an important error in the soil moisture product. The use of the polarization ratio at $6.9 \mathrm{GHz}$ provides a better agreement with simulated soil moisture. The spatialized soil moisture obtained using the VAS in situ observation is, in general, more in accordance with the AMSR-E products than the spatialized soil moisture data obtained using PERSIANN satellite estimates. The rainfall differences reported above are sometimes consequent and can produce considerable impacts on seasonal weather and climate forecasts when used for land surface model forcing. This indicates the importance of using the most accurate precipitation database, as large differences are in most of the cases directly translated into equally high errors in soil moisture. The satellite derived rainfall estimates seem to have potential to contribute to extending model simulations and water resource estimations into the future. Further work will imply simulation of the SMOS brightness temperature using the simulated soil moisture obtained from the presented work. After the Cal/Val process, comparison with SMOS data will give us more information about which precipitation database to be considered in our approach.

Acknowledgements. The authors wish to thank the European Space Agency (ESA), the Centre National d'Etudes Spatiales (CNES), the Centre National de la Recherche Scientifique - Institut National des Sciences de l'Univers (CNRS-INSU SIC) and the French National Programme TOSCA (Terre, Océans, Surfaces Continentales et Atmosphère) for supporting this work. We also wish to thank the NASA National Snow and Ice Data Center (NSIDC) for providing AMSR-E data. We thank also the Centre national de Recherches Météorologiques and Jean-Christophe Calvet (CNRM) - Météo-France for the SURFEX model as well as for the Land-SAF downwelling shortwave fluxes. The authors wish to thank also the Spanish Agency for Meteorology (AEMet) and to the Jucar River Basin Authority (CHJ) for the meteorological data.

Edited by: H. Cloke

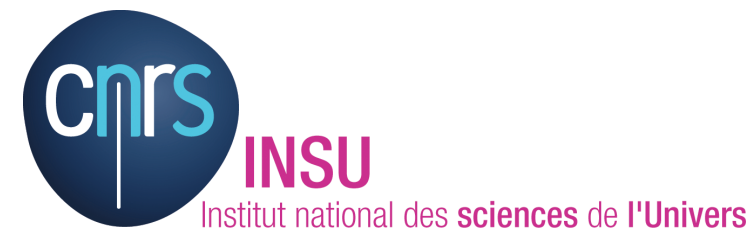

The publication of this article is financed by CNRS-INSU.

\section{References}

Boone, A.: Modelisation des processus hydrologiques dans le schema de surface ISBA: Inclusion d'un reservoir hydrologique, du gel et modelisation de la neige., $\mathrm{PhD}$ thesis, University Paul Sabatier, Toulouse, France, 252 pp., 2000.

Boone, A., Masson, V., Meyers, T., and Noilhan, J.: The influence of the inclusion of soil freezing on simulations by a soilvegetation-atmosphere transfer scheme., J. Appl. Meteor., 39, 1544-1569, 2000.

Brown, J. E. M.: An analysis of the performance of hybrid infrared and microwave satellite precipitation algorithms over India and adjacent regions, Rem. Sens. Environ., 101, 63-81, 2006.

Brutsaert, W. H.: On a derivable formula for long-wave radiation from clear skies, Water Resour. Res., 11(2), 742-744, 1975.

Cano, A., Millan-Scheiding, C., Wigneron, J.-P., Antolin, C., Balling, J., Grant, J., Kruszewski, A., Saleh, K., Sobjaerg, S., Skou, N., and Lopez-Baeza, E.: The Mediterranean Ecosystem L-Band EXperiment over vineyards (Melbex-2)., 10th Specialist Meeting on Microwave Radiometry and Remote Sensing for the Environment, Italy, 2008.

Collischonn, B., Collischonn, W., and Morelli Tucci, C.E.: Daily hydrological modeling in the Amazon basin using TRMM rainfall estimates, J. Hydrol., 360(1-4), 207-216, 2008.

Delwart, S., Bouzinac, C., and Wursteisen, P.: Overall SMOS Cal/Val Plan and Requirements, SMOS 7th Workshop, Esrin, 2007.

Grimes, D. and Diop, M.: Satellite-based rainfall estimation for river flow forecasting in Africa. Part 1. Rainfall estimates and hydrological forecasts., Hydrol. Sci. J., 48(4), 567-584, 2003.

Gruhier, C., de Rosnay, P., Hasenauer, S., Holmes, T., de Jeu, R., Kerr, Y., Mougin, E., Njoku, E., Timouk, F., Wagner, W., and Zribi, M.: Soil moisture active and passive microwave products: intercomparison and evaluation over a Sahelian site, Hydrol. Earth Syst. Sci., 14, 141-156, doi:10.5194/hess-14-1412010, 2010.

Gottschalck, J., Meng, J., Rodell, M., and Houser, P.: Analysis of Multiple Precipitation Products and Preliminary Assessment of Their Impact on Global Land Data Assimilation System Land Surface States, J. Hydrometeorol., 6, 573-598, doi:10.1175/JHM437.1, 2005.

Grayson, R. B., Western, A. W., Walker, J. P., Kandel, D. D., Costelloe, J. F. and Wilson, D. J.: Controls on patterns of soil moisture in arid and semi-arid systems, Chapter 7, Ecohydrology of Arid and Semi-Arid Ecosystems. Eds. P. DOrdorico and A. Porporato, Springer, The Netherlands, 341 p., 2006.

Hong, Y., Hsu, K., Gao, X., and Sorooshian, S.: Precipitation Estimation from Remotely Sensed Information using An Artificial Neural Network-Cloud Classification System., J. Appl. Met., 
43, 1834-1852, 2004.

Hsu, K., Gao, X., Sorooshian, S., and Gupta, H. V.: Precipitation estimation from remotely sensed information using artificial neural networks., J. Appl. Meteor., 36, 1176-1190, 1997.

Hsu, K., Gupta, H., Gao, X., and Sorooshian, S.: Estimation of physical variables from multi-channel remotely sensed imagery using a neural network: application to rainfall estimation., Water Resour. Res., 35(5), 1605-1618, 1999.

Hughes, D., Andersson, L., Wilk, J., and Savenije, H.: Regional calibration of the Pitman model for the Okavango River, J. Hydrol., 331(1-2), 30-42, 2006.

Hughes, D. A.: Comparison of satellite rainfall data with observations from gauging station networks., J. Hydrol., 327, 399-410, 2006.

Jackson, T. J., LeVine, D., Swift, C., Schmugge, T. J., and Schiebe, F.: Large area mapping of soil moisture using the ESTAR passive microwave radiometer., Rem. Sens. Environ., 54(1), 27-37, 1995.

Jackson, T. J., Le Vine, D. M., Hsu, A., Oldack, A., Starks, P., Swift, C., Isham, J., and Haken, M.: Soil moisture Mapping at regional scales using microwave radiometry: The southern great plains hydrology experiment, IEEE Trans. Geosc. Remote Sens., 37(5), 2136-2151, 1999.

Juglea, S., Kerr, Y., Mialon, A., Wigneron, J.-P., Lopez-Baeza, E., Cano, A., Albitar, A., Millan-Scheiding, C., Carmen Antolin, M., and Delwart, S.: Modelling soil moisture at SMOS scale by use of a SVAT model over the Valencia Anchor Station, Hydrol. Earth Syst. Sci., 14, 831-846, doi:10.5194/hess-14-831-2010, 2010.

Kerr, Y. H. and Njoku, E. G.: A semi empirical model for interpreting microwave emission from semiarid surfaces as seeen from space, IEEE Trans. Geosc. Remote Sens., 28, 384-393, 1990.

Kerr, Y. H., Waldteufel, P., Wigneron, J.-P., Martinuzzi, J.-M., Font, J., and Berger, M.: Soil moisture retrieval from Space: The soil moisture and ocean salinity (SMOS) mission, IEEE Trans. Geosc. Remote Sens., 39(8), 1729-1735, 2001.

Le Moigne, P., Boone, A., Calvet, J.-C., Decharme, B., Faroux, S., Gibelin, A.-L., Lebeaupin, C., Mahfouf, J.-F., Martin, E., Masson, V., Mironov, D., Noilhan, J., Tulet, P., and Van Den Hurk, B.: SURFEX scientific documentation, 2009.

Lopez-Baeza, E., Antolin Tomas, C., Bodas Salcedo, A., Gimeno Ferrer, J. F., Saleh Contell, K., Ferrer, F., Castell Balaguer, N., Domenech Garcia, C., Sanchez Alandi, M. A., and Velazquez Blazquez, A.: The Valencia Anchor Station: A Reference Cal/Val Area for Low-Resolution Remote Sensing Data and Products., Recent Advances in Quantitative Remote Sensing, Torrente (Valencia), poster, 2002.

Lopez-Baeza, E., Alonso, S., Comeron, A., Diaz-Pabon, R., Domenech, C., Gimeno-Ferrer, J., Jorge, J., Labajo, A., Pineda, N., Pino, D., Rius, A., Rocadenbosch, F., Saleh, K., Sicard, M., Tarruella, R., Torrobella, J., and Velazquez, A.: A High-Quality Dataset of Land-Surface and Atmospheric Measurements for the Comparison/Crosscalibration of Data From Large Scale Optical Earth Observation Sensors in Space. The Valencia Anchor Station., Proceedings of the Workshop on Inter-Comparison of Large Scale Optical and Infrared Sensors, ESA/ESTEC 12-14 October 2004, ESA-WPP-244, 2005a.
Lopez-Baeza, E., Domenech, C., Gimeno-Ferrer, J., and Velazquez, A.: Proposal of a Water Cycle Observatory: The Reference Valencia and Alacant Anchor Stations for Remote Sensing Data and Products., XI Spanish Remote Sensing Congress, Puerto de la Cruz, Tenerife, 2005b.

Lopez-Baeza, E., SVRC, and team: Validation of SMOS Products over Mediterranean Ecosystem Vegetation at the Valencia Anchor Station Reference Area, Experimental Plan SMOS Validation Rehearsal Campaign, SMOS Cal/Val AO I.D, 2008.

Masson, V., Champeaux, J.-L., Chauvin, F., Meriguet, C., and Lacaze, R.: A global database of land surface parameters at 1$\mathrm{km}$ resolution in meteorological and climate models, J. Climate, 16(9), 1261-1282, 2003.

Millan-Scheiding, C., Marco, J., Soriano, M., Torre, E., Torregrosa, G., Abalos, B., Requena, F., Cano, A., Antolin, C., and LopezBaeza, E.: VAS Soil and Vegetation Characterization, SMOS meeting in Bordeaux, INRA, 30-31 October 2008.

Ming, P., Li, H., and Wood, E. F.: Assessing the Skill of Satellitebased Precipitation Estimates in Hydrologic Applications, Water Resour. Res., in press, 2010.

Njoku, E. G.: AMSR-E/AQUA daily L3 surface soil moisture, interpretive parms, \& QC EASE-Grids, Boulder, CO, USA: National Snow and Ice Data Center, Digital Media, 2004.

Njoku, E. G., Jackson, T., Lakshmi, V., Chan, T., and Nghiem, S.: Soil moisture retrieval from AMSR-E, IEEE Geosc. Remote Sens. Lett., 41(2), 215-229, 2003.

Noilhan, J. and Mahfouf, J.-F.: The ISBA land surface parameterization scheme, Global Planet. Change, 13, 145-159, 1996.

Noilhan, J. and Planton, S.: A simple parameterization of land surface fluxes processes for meteorological models, Mon. Weather Rev., 117, 536-549, 1989.

Owe, M., De Jeu, R. A. M., and Walker, J. P.: A Methodology for Surface Soil Moisture and Vegetation Optical Depth Retrieval using the Microwave Polarization Difference index, IEEE Trans. Geosc. Remote Sens., 39(8), 1643-1654, 2001.

Rüdiger, C., Calvet, J.-C., Gruhier, C., Holmes, T. R. H., de Jeu, R. A. M., and Wagner, W.: An Intercomparison of ERSSCAT and AMSR-E Soil Moisture Observations with Model Simulations over France, J. Hydrometeorol., 10(2), 431-447, doi:10.1175/2008JHM997.1, 2009.

Schmugge, T., Jackson, T., Kustas, T. J., and Wang, J. R.: Passive microwave remote sensing of soil moisture: results from HAPEX, FIFE and MONSOON'90, ISPRS J. Photogramm., 47, 127-143, 1992.

Seed, A. and Austin, G.: Variability of summer Florida rainfall and its significance for the estimation of rainfall by gages, radar and satellite., J. Geophys. Res., 95, 2207-2216, 1990.

Sorooshian, S., Hsu, K., Gao, X., Gupta, H., Imam, B., and Braithwaite, D.: Evaluation of PERSIANN system satellite-based estimates of tropical rainfall., B. Am. Meteorol. Soc., 81, 20352046, 2000.

Thorne, V., Coakley, P., Grimes, D., and Dugdale, G.: Comparsion of TAMSAT and CPC rainfall estimates with rainfall, for Southern Africa., Int. J. Remote Sens., 22(10), 1951-1974, 2001.

Wang, J. R., Shiue, J., Schmugge, T., and Engman, E. T.: The L-band PBMR measurements of surface soil moisture in FIFE, IEEE Trans. Geosc. Remote Sens., 28, 906-914, 1990a. 
Wagner, W., Naeimi, V., Scipal, K., de Jeu, R., and MartínezFernández, J.: Soil moisture from operational meteorological satellites, Hydrogeol. J., 15(1), 121-131, doi:10.1007/s10040006-0104-6, 2007.
Wilk, J., Kniveton, D., Andersson, L., Layberry, R., Todd, M., Hughes, D., Ringrose, S., and Vanderpost, C.: Estimating rainfall and water balance over the Okavango River Basin for hydrological applications., J. Hydrol., 331(1-2), 18-29, 2006. 